\title{
Analysis of the ground-source heat pump operation with various heat-carrier fluids in the lower heat source
}

\author{
Ewelina Stefanowicz ${ }^{1, *}$, Matgorzata Szulgowska-Zgrzywa ${ }^{1}$, Natalia Fidorów-Kaprawy $^{1}$ \\ ${ }^{1}$ Wrocław University of Science and Technology, Wybrzeże Stanisława Wyspiańskiego 27, 50-370 \\ Wrocław, Poland
}

\begin{abstract}
In the paper the analysis of the operation of ground-source heat pump with various heat-carrier fluids circulating in boreholes was made. The authors considered several aspects related to the heat-carrier fluid selection (freezing point, heat transfer capabilities, toxicity, pumping costs). The lower heat source analysis had been performed in Earth Energy Designer (EED) software. The analyses' results reliability was assured by the ground-source model calibration made basing on the measurement data from on-site test stand. Analyses were performed for four heat-carrier fluids (two kinds of propylene glycol solutions - standard and with lower viscosity, water and nanofluid (water $+\mathrm{CuO})$ ) and in four variants of thermal load (design and actual loads both with and without active regeneration). It had been concluded that temperature of none of the fluids would drop under $0^{\circ} \mathrm{C}$ if the system was operated under actual thermal load. For design thermal load there would be a risk of the water freezing but it may be minimized by active regeneration or lower heat source enlargement by $20 \%$ (in analyzed case) each rising the mean fluid temperature by around $1.0-1.5 \mathrm{~K}$. The use of other fluid in place of standard propylene glycol solution will give pumping energy savings.
\end{abstract}

\section{Introduction}

One of the basic parameters characterizing the properties of the heat-carrier fluids in Ground Source Heat Pump systems (GSHPs) is the freezing temperature. Despite the fact that the fluid temperature in properly designed closed loops of ground source in the period of the highest heat demand should not fall below $0{ }^{\circ} \mathrm{C}$, the heat-carrier fluids with freezing points about $-12^{\circ} \mathrm{C}$ are used in practice. Initially, $\mathrm{NaCl}$ solutions were used as antifreeze fluids for GSHPs. However, due to their corrosive nature, they were replaced by glycols of various concentrations. Other properties characterizing the heat-carrier fluids are viscosity and density. Ideally, their values should be similar to those for water. These properties have a direct effect on the flow resistance in the Borehole Heat Exchanger (BHE). Another issue is the safety of both the user and the environment. The fluid should be non-toxic and in case of any failure should not have a negative impact on the natural environment. Water could

\footnotetext{
${ }^{*}$ Corresponding author: ewelina.stefanowicz@pwr.edu.pl
} 
be used as a heat-carrier fluid, however to prevent from freezing in winter, antifreeze substances are added. To prevent the growth of the microorganisms and the fungi in pipes, the corrosion inhibitors and the biocides ( $<5 \%$ by weight) are added [1]. The perfect heatcarrier fluid used in BHE should be nontoxic and biodegradable under both aerobic and anaerobic environment, without producing toxic and/or stable intermediates.

According to the toxicological profile published by the Agency for Toxic Substances and Disease Registration (ATSDR) and the Environmental Protection Agency (EPA) - the US federal Agency [2,3] ethylene and propylene glycol are colorless and odorless synthetic substances that absorb water. The glycols are degraded both with air and water. What is important, these substances, although lowering the freezing point of the heat-carrier fluid, significantly reduce its thermal conductivity. Considered to be toxic, ethylene glycol is increasingly replaced by propylene glycol - a safer one but with much worse thermal properties.

Researchers are focusing on improving the thermal properties of the heat-carrier fluids e.g. by adding the solid particles to the solutions. The contemporary nanotechnology allows to obtain the particles with a size of $50 \mathrm{~nm}$, thus allowing the creation of new, better heatcarrier fluids called nanofluids [4]. This concept was introduced by Choi [5] and describes slurry with better thermal parameters than the base liquid. Such substances are obtained through the dispersion of solid particles, e.g. aluminum oxide $\left(\mathrm{Al}_{2} \mathrm{O}_{3}\right)$ and copper oxide $(\mathrm{CuO})$ in the base liquid (e.g. water). As a result, the new fluid has larger specific surface area, better thermal parameters and does not generate the problems related to clogging or abrasion. Nanofluids were extensively studied and the scientists proved a significant increase in the thermal properties of fluids at low particle concentrations $[4,6,7]$.

One of the best heat-carrier fluids is water. Due to its physicochemical properties, low density and viscosity, no negative impact on the environment and low operating costs, it is well suited to many systems. However, water is not a commonly used fluid in GSHPs due to the risk of freezing. However, there is a possibility to analyze the work of the system and accurate closed loops size design in a way to protect the system against the fluid temperature drop below $0^{\circ} \mathrm{C}$.

In this article, the authors analyzed whether in the real system the use of the environment neutral heat-carrier fluid, like water or nanofluid, would be possible despite the limitations associated with the higher freezing temperature. Based on the measurement data from the BHEs system, the model of the average heat-carrier fluid temperature calculation was calibrated. Using it, the simulation of the operation of this system was carried out in several variants. The average fluid temperatures were calculated using the Earth Energy Designer (EED) software. In addition, the pressure losses in the system were calculated as well as the energy used for the work of the circulation pump and, ultimately, the SCOP of the system.

\section{Ground parameters for the simulation purposes}

In the previous papers $[8,9]$ the authors discussed the problem of the proper simulation input data acquisition. It had been proved that the input data have a significant impact on simulation results [8] and do not give the certainty of the simulation and the subsequent operation results compliance [9].

In the first paper [8] it had been proved that the available calculation methods give various values of the soil heat transfer coefficient. The calculation of the lower's heat source size based on the assumed unit heat yield from the ground is a commonly used computational practice. The reduction of the system efficiency may be visible already in the first years of operation and depends on the actual discrepancy between the assumptions and the real properties of the ground. The knowledge of the soil profile allows for the 
application of the more accurate method. On its basis, thermal conductivity of the ground and its volumetric heat capacity are determined using tabular plots. However, the determination the of soil saturation level is problematic. As it turned out, the differences are significant. There are also various guidelines concerning the relation of the unit heat output to the thermal conductivity of the soil. The most accurate method for obtaining input data for the heat pumps' GHE performance simulation, used nowadays, is the TRT (Thermal Response Test). Discussion on discrepancies that may arise as a result of these tests was carried out in the second of the quoted articles [9]. The TRT [10, 11] allows determining the effective thermal conductivity of the ground and the borehole resistance. The TRT was carried out on an existing installation and, as demonstrated, the use of this technique, did not allow obtaining correct results due to a number of the measurement disturbing conditions, among others advection or flow of groundwater. The size of the lower heat source, designed based on the TRT in the examined system, would result in its excessive cooling already in the first years of operation - regardless of the source active regeneration in the summer or its lack. This was demonstrated by executing a performance test on a reduced number of boreholes, corresponding to the TRT result. The consequences of the disturbances influence of the TRT results have been described in articles $[12,13]$. The authors also showed that the flow rate of the groundwater limits the TRT application. The obtained thermal conductivity values include the effects of convection and the thermal conductivity of the ground is masked where flow rate of groundwater is high; in those cases the obtained value cannot be used for BHE installation design.

In conclusion: many articles point out the lack of a good method for the calculation of operational effectiveness of boreholes. Works on improving TRT are conducted by many researchers and described in publications [10-13]. This article concerns the simulation of the operation of an exemplary ground source heat pump system with various heat-carrier fluids. Due to the fact that the application of heat-carrier fluids that freeze in $0{ }^{\circ} \mathrm{C}$ had also been proposed, the authors considered it important to provide the most accurate input data regarding ground parameters. As a result, the BHE model was calibrated based on available measurement data.

Simulation of the heat pump's BHE performance was carried out in the EED software. The calibration of the BHE model was carried out using the measurement data from two boreholes of the operating heat pump system. For calibration purposes three sets of data were selected ( $\lambda$ - the thermal conductivity of the ground, $\mathrm{Cv}$ - volumetric heat capacity of the ground), based on literature and previous studies $[8,9,14]$ :

- Set $1: \lambda=1.0 \mathrm{~W} /(\mathrm{m} \cdot \mathrm{K})$ and $\mathrm{Cv}=1.5 \mathrm{MJ} /\left(\mathrm{m}^{3} \cdot \mathrm{K}\right)$,

- Set $2: \lambda=1.5 \mathrm{~W} /(\mathrm{m} \cdot \mathrm{K})$ and $\mathrm{Cv}=2.4 \mathrm{MJ} /\left(\mathrm{m}^{3} \cdot \mathrm{K}\right)$,

- Set $3: \lambda=3.5 \mathrm{~W} /(\mathrm{m} \cdot \mathrm{K})$ and $\mathrm{Cv}=2.5 \mathrm{MJ} /\left(\mathrm{m}^{3} \cdot \mathrm{K}\right)$.

The first borehole was operated only with energy intake in winter and was not actively regenerated during the summer. Basing on the available measurement data (temperatures of: ground surface, borehole and heat-carrier fluid, and the borehole heat loads), the parameters of the ground were selected so, as to best reflect the actual temperature of the heat-carrier fluid in the following months $\left(\mathrm{T}_{\mathrm{avg}}\right)$. The simulation results for three data sets are shown in Fig.1. In the analyzes, in addition to the value describing the thermal conductivity of the ground and its heat capacity, attention should be paid to the temperature of the ground surface. It is an extremely important boundary parameter, from which the calculation of undisturbed ground temperature around BHE begins. Specifying an incorrect value significantly changes the simulation results. In the following calibration, the ground surface temperature of $8.9^{\circ} \mathrm{C}$ (calculated as the average temperature of the outside air from the previous year) was assumed as the initial value. This resulted, for the best data set (Set 2: $\lambda=1.5 \mathrm{~W} /(\mathrm{m} \cdot \mathrm{K})$ and $\mathrm{Cv}=2.4 \mathrm{MJ} /\left(\mathrm{m}^{3} \cdot \mathrm{K}\right)$ ), with the borehole temperature of $10.46^{\circ} \mathrm{C}$. Actual borehole temperature was $10.9^{\circ} \mathrm{C}$, so the compatibility is very good. The 
average relative uncertainties of the heat-carrier fluids average temperature $\left(\mathrm{T}_{\text {avg }}\right)$ simulation in individual months are: 15\% (set 1), 12\% (set 2) and 13\% (set 3).

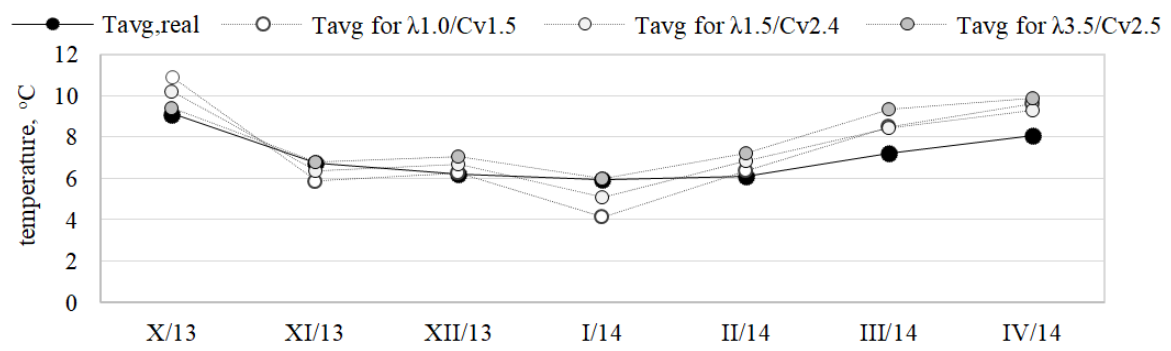

Fig. 1. The average ground temperature model and real measurements in the not regenerated borehole.

Afterwards a comparative analysis of the simulation results with the measurement data from the borehole actively regenerated in the summer was carried out. The heating and cooling loads, according to the measurements data, were introduced into the EED software. The simulation results for three parameter sets are shown in Fig. 2. The actual initial temperature of the borehole was $11.5^{\circ} \mathrm{C}$. Compatibility with simulations for individual parameter sets $\left(11.34^{\circ} \mathrm{C}, 11.56^{\circ} \mathrm{C}\right.$ and $\left.11.67^{\circ} \mathrm{C}\right)$ is very good. The average relative uncertainties of the heat-carrier fluid average temperature $\left(\mathrm{T}_{\mathrm{avg}}\right)$ simulation in individual months are: $18 \%$ (set 1$), 13 \%$ (set 2 ) and $25 \%$ (set 3 ).

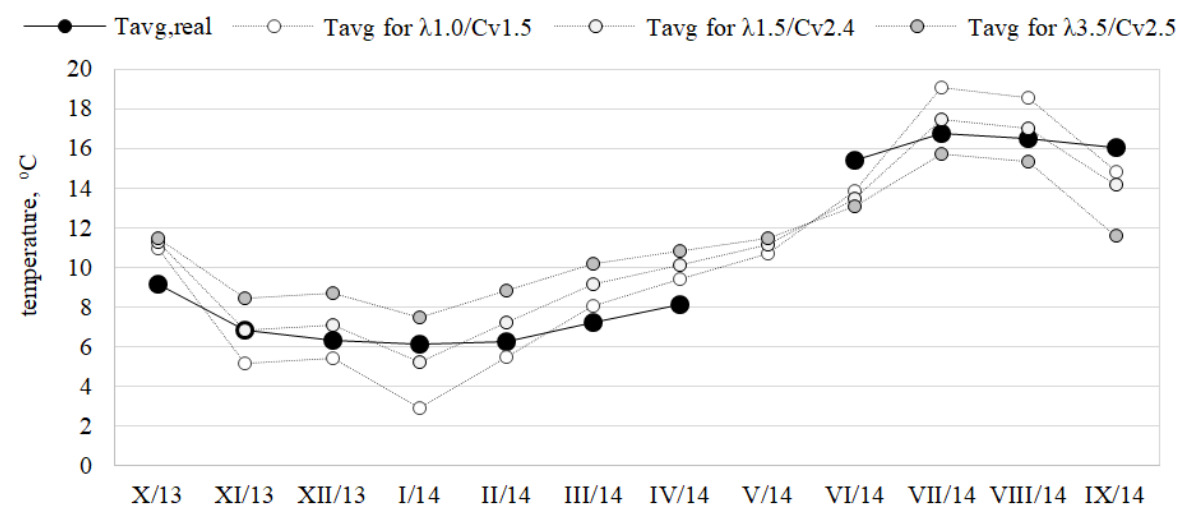

Fig. 2. The average ground temperature model and real measurements in the regenerated borehole.

Ground parameters adopted for further analysis are set 2, i.e. thermal conductivity $\lambda=1.5 \mathrm{~W} /(\mathrm{m} \cdot \mathrm{K})$ and volumetric heat capacity $\mathrm{Cv}=2.4 \mathrm{MJ} /\left(\mathrm{m}^{3} \cdot \mathrm{K}\right)$. These data ensured a very good agreement of the calculated initial temperature of the borehole and the temperature of the heat-carrier fluid in the following months with the measurements.

\section{The installation description and analysis variants}

The lower heat source of the analyzed heat pump system consists of five vertical boreholes $78 \mathrm{~m}$ long each. These are U-tube probes with a diameter of $40 \times 3.7 \mathrm{~mm}$. The boreholes are arranged in the "L" configuration at a distance of $5 \mathrm{~m}$ from each other. The diameter of the single borehole is $110 \mathrm{~mm}$. Boreholes are filled with the material with thermal conductivity 
of $0.6 \mathrm{~W} /(\mathrm{m} \cdot \mathrm{K})$. The boreholes are heat source for the ground-source heat pump having thermal power of $17.6 \mathrm{~kW}$ with COP 4.4 for $\mathrm{B} 0 / \mathrm{W} 35$ parameters and $21.6 \mathrm{~kW}$ and COP 5.1 for B10/W35 parameters.

Design of the heat pumps' lower heat sources is based mainly on the design heating load of the installation. The size and configuration of vertical probes is assumed basing on this load. The actual heat demand of a building in the climate prevailing in Poland is significantly lower. It was decided to carry out the analysis of the installation performance under the design heating load (B, D) and the actual load (A, C). The thermal load in variant $\mathrm{A}$ is $13000 \mathrm{kWh} / \mathrm{y}$. This is the actual average heating load of the object from three years of operation. The thermal load B is the value of heat demand for the conditions of the standard season in this location. It equals $27000 \mathrm{kWh} / \mathrm{y}$. Variants $\mathrm{C}$ and $\mathrm{D}$ include the active regeneration of the lower heat source in summer using the solar collectors. The amount of regenerative energy $(6300 \mathrm{kWh} / \mathrm{y})$ is an average value from three years of operation.

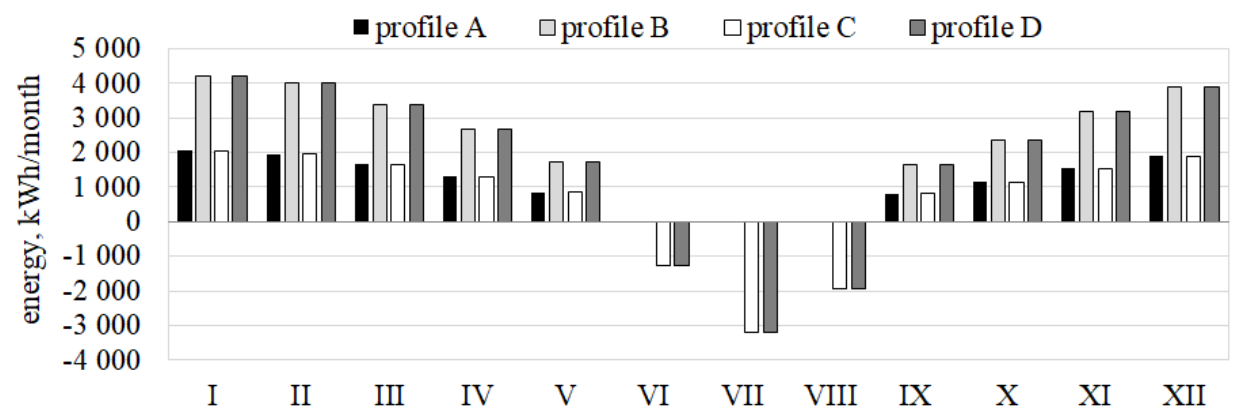

Fig. 3. The heating load of the building and the active regeneration profiles in analyzed variants.

Each variant of the analysis was performed for a propylene glycol solution (PG_1), propylene glycol solution with reduced viscosity ( $\left.\mathrm{PG}_{-} 2\right)$, water and nanofluid (water $+\mathrm{CuO}$ ). Fig. 4. presents the thermal parameters of selected liquids. Propylene glycols are commonly used heat-carrier fluids in heat pumps' ground heat exchangers due to low freezing temperatures. It is not recommended to use water in such systems due to the risk of freezing. The heat-carrier fluid introduced to the lower heat sources' installations in laboratory conditions are nanofluids. It can be noticed that while the characteristic thermal properties of the presented liquids do not differ significantly, the dynamic viscosity, affecting the pumping costs, in the case of glycol is much higher.
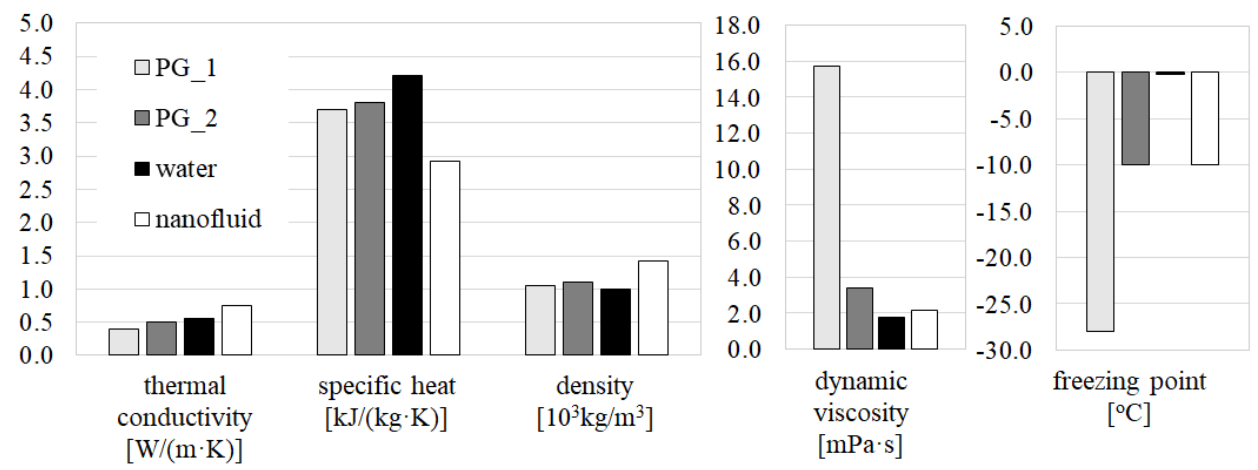

Fig. 4. The physicochemical parameters of the selected heat-carrier fluids. 
The operation of boreholes with different heat-carrier fluids results in different Reynolds numbers $(\mathrm{Re})$ values, thermal conductivity and resistance while maintaining the same flow rate $\left(0.504 \mathrm{~m}^{3} / \mathrm{h}\right.$ per borehole). These differences were presented in Table 1 .

Table 1. The BHE parameters for the selected heat-carrier fluids.

\begin{tabular}{ll|rrrr} 
Thermal resistance & & PG_1 & water & PG_2 & nanofluid \\
\hline Reynolds number & - & 357 & 3037 & 1785 & 3697 \\
Effective BHE thermal resistance & $(\mathrm{m} \cdot \mathrm{K}) / \mathrm{W}$ & 0.2502 & 0.1517 & 0.2282 & 0.1497
\end{tabular}

\section{Discussion of results}

\subsection{Heat-carrier fluid temperatures}

The following figures $(5,6)$ present the effect of the analyzed loads on the long-term operation of the installation. The influence of these loads on the system work is represented by the average fluid temperature (between the flow and the return) in the subsequent months of the $10^{\text {th }}$ year of system operation.

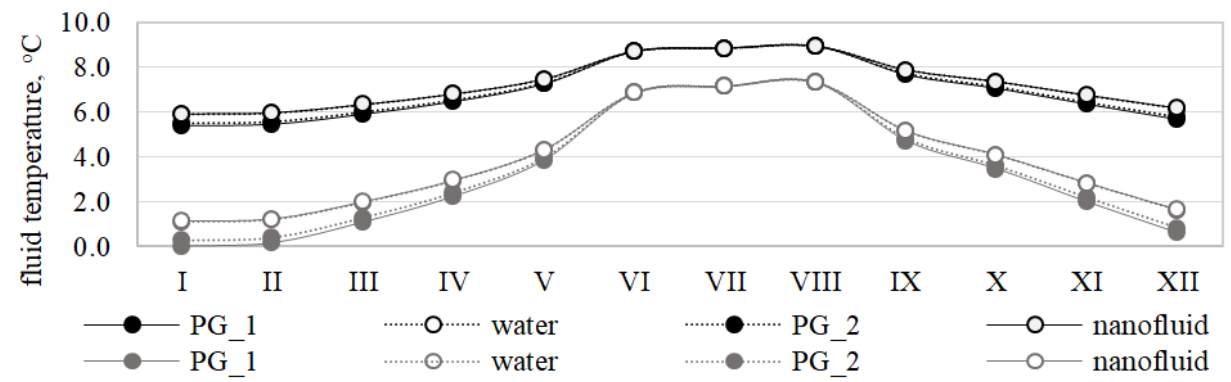

Fig. 5. Average heat-carrier fluid flow and return temperatures in the $10^{\text {th }}$ year of the system operation without regeneration for designed (B-gray) and real (A-black) heating load.

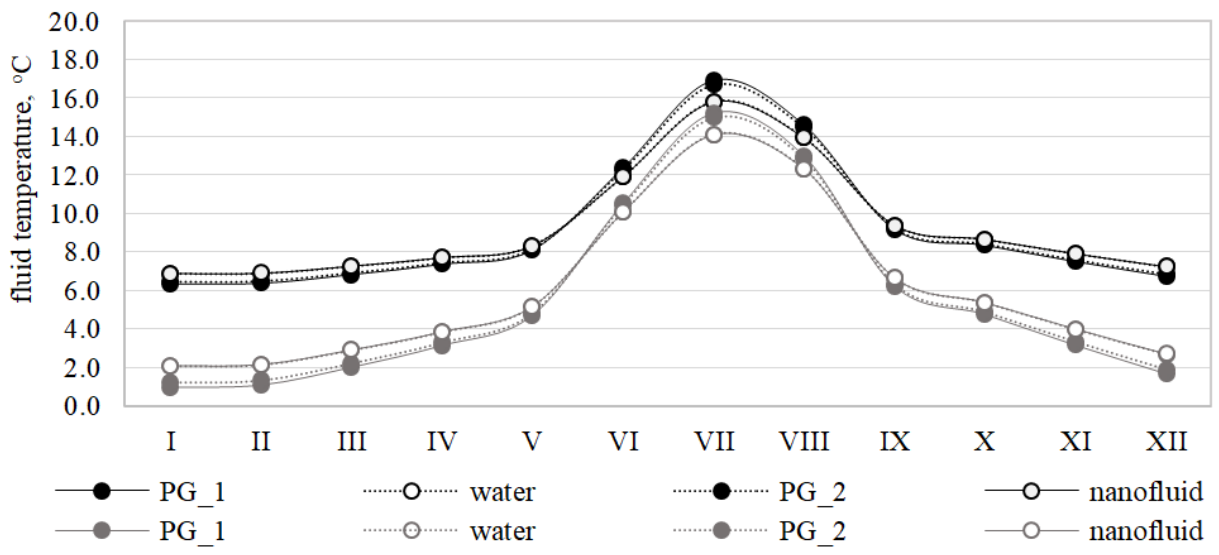

Fig. 6. Average heat-carrier fluid flow and return temperatures in the $10^{\text {th }}$ year of the system operation with regeneration for designed (B-gray) and real (A-black) heating load.

For the same variants of the heat load, the fluids' temperatures are almost contiguous. The design heating load is twice as large as the real one - despite this, the average fluids' 
temperatures in the $10^{\text {th }}$ year of operation never drops below $0^{\circ} \mathrm{C}$. The active regeneration additionally protects the system by raising the average fluid temperature in winter by about $1 \mathrm{~K}$. As the figures $(5,6)$ present the average fluid temperature, there is some risk remaining of the return fluid temperature from the heat pump dropping below $0^{\circ} \mathrm{C}$ periodically. The use of water as the heat-carrier fluid in this closed loop system would require changing the protection set point in heat pump from $-5^{\circ} \mathrm{C}$ to $0^{\circ} \mathrm{C}$. The performed analyzes shown that the parameters of the considered heat-carrier fluids do not show the differences that would have a significant impact on the fluid temperature in the subsequent months of the system operation. It should be noted that the same fluid volumetric flow was assumed in the analyzed variants. At the same time, there are differences in the values of the Reynolds numbers for each fluid. For glycols, this value indicates laminar flow. For water and nanofluid, the flow is turbulent and it would be possible to design a larger low-heat source for the heat pump system (based on six boreholes) while maintaining turbulent flow. This would allow to rise the fluid temperature by approximately $1.5 \mathrm{~K}$. At the same time, with an additional frost protection, this will allow further reduction of pressure loss in the system.

\subsection{Pressure loss}

In GSHPs systems a significant amount of electricity is consumed by the circulating pump work. Due to the fact that the use of any of the four fluids for which the analyzes were carried out gives the similar fluid temperatures in the evaporator (which results in the similar heat pump efficiency), the authors decided to analyze the system efficiency including energy consumption for the pumping process. In the engineering practice, often the pressure losses calculated during design process do not coincide with the reality. This is the reason why the authors decided to use the operational data to verify the assumptions related to the calculation of pressure loss in the BHE. For the real installation in which $45 \%$ propylene glycol solution was the heat-carrier fluid, the calculated pressure loss is $6.18 \mathrm{mH}_{2} \mathrm{O}$ with a flow value of $2.52 \mathrm{~m}^{3} / \mathrm{h}$ (corresponding to the actual flow through the ground source). The value of the pressure loss corresponds to the operating point of the circulating pump installed in the heat pump. Assuming the same construction of the installation, the pressure loss were calculated for the remaining analyzed fluids. On the basis of the designated work points, the appropriate circulation pumps were selected, the electric power of the pumps at the work points was determined and the energy consumed annually was calculated on the basis of the installation's work time for the thermal load variant (A). Table 2. presents the summary of the calculation results.

Table 2. Comparison of the pressure loss in the system (variant A) for the analyzed fluids.

\begin{tabular}{c|cccccc} 
No. & Fluid & $\begin{array}{c}\text { Head } \\
{[\mathbf{m H} \mathbf{O} \text { ] }}\end{array}$ & $\begin{array}{c}\text { Power } \\
{[\mathbf{W}]}\end{array}$ & $\begin{array}{c}\text { Operating } \\
\text { time }[\mathbf{h}]\end{array}$ & $\begin{array}{c}\text { Energy } \\
\text { consumption } \\
{[\mathbf{k W h}]}\end{array}$ & $\begin{array}{c}\text { Energy } \\
\text { savings }\end{array}$ \\
\hline 1 & PG1 & 6.18 & 102 & & 104 & - \\
2 & PG2 & 5.44 & 80 & 1023 & 82 & $21.6 \%$ \\
3 & water & 2.56 & 35 & & 36 & $65.7 \%$ \\
4 & nanofluid & 2.80 & 54 & & 55 & $47.1 \%$
\end{tabular}

The calculation results suggest that the use of the different heat-carrier fluids may cause significant differences in auxiliary energy consumption for the BHE circulating pump. The differences in the auxiliary energy consumption for such a small installation will not have a significant impact on operating costs, but for large systems they will be an important aspect of the economic justification of such a solution. 


\section{Conclusions}

In the paper, the analysis of the operation of ground-source heat pump system in cooperation with the various heat-carrier circulating in the boreholes was conducted. As shown, basing on the calibrated boreholes model, the differences in the average fluids' temperatures in the example year of system operation for the same flow rate are small. At a real heat demand, average fluids' temperatures never fall below $0^{\circ} \mathrm{C}$, staying at the level of $5^{\circ} \mathrm{C}$. However, the long-term system operation with the design heat demand increases the risk of the occurrence of the negative temperatures of the fluid. Therefore, when using water as the heat-carrier fluid, the system should be additionally protected. This can be done by using active regeneration and/or by enlarging ground heat exchanger. Each of these improvements increases the average fluid temperature by about $1.0-1.5 \mathrm{~K}$. The analyzes show that the pressure loss generated by water and the nanofluid are significantly lower than for the glycol solutions. The amount of electricity needed by the circulating pump is $65 \%$ lower when comparing the system using water to one with propylene glycol. Due to the small differences in the average fluids' temperatures, SCOP does not differ significantly. Taking into account the electric energy needed to supply the circulating pumps, SCOP is 4.84 (for water) and 4.70 (for glycol). For a larger lower heat source, the SCOP increases to 4.90 (for water). The operating costs of the systems will therefore be comparable. However, the environmental aspect and the significantly lower investment costs for filling the installation with water (not with propylene glycol) remain important. In conclusion, the results of the simulation are promising but there is need for the analyzes of the real BHE systems working with water or nanofluid.

\section{Bibliography}

1. T. Klotzbucher, A. Kappler, K.L. Straub, S.B. Haderlein, Geothermics, 36, 348-361 (2007)

2. Reregistration Eligibility Decision For Propylene Glycol and Dipropylene Glycol, (US EPA, Washington, D.C., USA, published online as pdf, 2006)

3. Toxicological profile for ethylene glycol and propylene glycol, (US Department of Health and Human Services, Agency for Toxic Substances and Disease Registry, Atlanta, GA, USA, published online as pdf, 1997)

4. S.M. Fotukian, M. Nasr Esfahany, Int. Commun. Heat. Mass., 37, 214-219 (2010)

5. S.U.S. Choi, J.A. Eastman, Developments and Applications of Non-newtonian Flows FED, 231/MD 66, 99-105 (1995)

6. G. Emmi, S. Zarrella, M. De Carli, M. Dona, A. Galgaro, Geothermics, 65, 158-169 (2017)

7. M. Doneshipour, R. Rafee; Int. Commun. Heat. Mass., 81, 34-41 (2017)

8. E. Stefanowicz, N. Fidorów-Kaprawy, E3S Web of Conferences, 17 (2017)

9. N. Fidorów-Kaprawy, E. Stefanowicz, W. Mazurek, M. Szulgowska-Zgrzywa, A. Bryszewska-Mazurek, E3S Web of Conferences, 22 (2017)

10. J. Acuna, P. Mogensen, B. Palm; Appl. Energy, 109, 312-320 (2009)

11. J.D. Spitler, S.E.A. Gehlin, Renew. Sust. Energ. Rev., 50, 1125-1137 (2015)

12. C. Zhang, Z. Guo, Y. Liu, X. Cong, D. Peng, Renew. Sust. Energ. Rev., 40, 851-867 (2014)

13. A. Liuzzo-Scorpo, B. Nordell, S. Gehlin, Geothermics, 56, 119-127 (2015)

14. P. Koorevaar, G. Menelik, C. Dirksen, Elements of Soil Physics, 13, 115-123 (1983) 